\title{
COMPARISON OF EFFICACY OF SEVOFLURANE AND DESFLURANE IN SURGICAL PROCEDURES LASTING LESS THAN 120 MINUTES
}

\author{
Aparanji Koduri1, Sateesh Kumar Potnuru², Charishma Basina ${ }^{3}$ \\ ${ }_{1}^{1}$ Associate Professor, Department of Anaesthesiology, Andhra Medical College, Visakhapatnam. \\ ${ }^{2}$ Assistant Professor, Department of Anaesthesiology, Andhra Medical College, Visakhapatnam. \\ ${ }^{3}$ Senior Resident, Department of Anaesthesiology, Andhra Medical College, Visakhapatnam.
}

\begin{tabular}{l}
\hline ABSTRACT \\
BACKGROUND \\
An ideal general anaesthetic should provide smooth and rapid induction, optimal surgical conditions, and rapid recovery with \\
minimal side effects. Volatile anaesthetics allow rapid emergence from anaesthesia because of easy treatability that makes them \\
more suitable for short surgical procedures. \\
Aim- To compare intraoperative haemodynamic and postoperative recovery profiles between Desflurane and Sevoflurane as \\
maintenance anaesthetic agents in patients undergoing short surgical procedures.
\end{tabular}

\section{MATERIALS AND METHODS}

This is a prospective randomised study that is conducted in patients undergoing short surgical procedures (duration $<120$ minutes). 60 patients belonging to ASA I or II scheduled for surgical procedures received Sevoflurane (30) and Desflurane (30) for maintenance of anaesthesia. Haemodynamics, recovery parameters like spontaneous eye opening, modified Aldrete score were recorded in PACU at regular time intervals. Score of 10 is considered as clear headedness and complete recovery from anaesthe tic effect.

\section{RESULTS}

The time taken for spontaneous eye opening is shorter in desflurane group. Early recovery with clear headedness from anaesthesia is significantly faster in Desflurane as compared to Sevoflurane.

\section{CONCLUSION}

Desflurane produces faster emergence and early recovery from anaesthesia than Sevoflurane. Intraoperative haemodynamic parameters are similar in both Desflurane and Sevoflurane anaesthesia.

\section{KEYWORDS}

Modified Aldrete Score, Desflurane, Sevoflurane, Emergence from Anaesthesia, Short Surgical Procedures.

HOW TO CITE THIS ARTICLE: Koduri A, Potnuru SK, Basina C. Comparison of efficacy of sevoflurane and desflurane in surgical procedures lasting less than 120 minutes. J. Evolution Med. Dent. Sci. 2018;7(02):183-187, DOI: 10.14260/jemds/2018/41

\section{BACKGROUND}

In modern practice of general anaesthesia, maintenance of anaesthesia in balanced proportion is done by volatile anaesthetics. These volatile agents are much more useful in short surgical procedures. The use of rapid and short acting intravenous anaesthetics, volatile anaesthetics, and muscle relaxants in anaesthesia helps in faster recovery of patients from anaesthesia in short surgical procedures.

General anaesthesia is often fairly preferred by patients because of their desire to be unaware of the procedure and favourable properties like minimal postoperative side effects and allowing quick and faster recovery. Easier control of depth of intraoperative anaesthesia and rapid recovery is possible with volatile agents.

The ideal volatile anaesthetics must have certain properties like chemical purity, good stability on metabolism by the body, no organ specific body effects on vital functions,

'Financial or Other Competing Interest': None.

Submission 22-11-2017, Peer Review 20-12-2017,

Acceptance 26-12-2017, Published 08-01-2018.

Corresponding Author:

Sateesh Kumar Potnuru,

Flat No. 3.2, Ramya Enclave,

D. No. 9-6-24,

Shivajipalem, Visakhapatnam-530017.

E-mail: drsateeshrims@yahoo.co.in

DOI: $10.14260 /$ jemds $/ 2018 / 41$ good analgesic effects, and shorter acting effects on central nervous system.

Volatile agents were introduced in 19th century firstly Ether in 1846 by W. T. G. Morton who demonstrated on animals initially, later in 1847 Chloroform was used to give anaesthesia by Simpson in obstetric anaesthesia. Then later newer generations of halogenated hydrocarbon anaesthetics were introduced by replacing the hydrogen atom with fluorine atom to decrease flammable property of the inhalational agents. Halothane was first of its kind, which further initiated to the development of Isoflurane.

The search for even more pharmacologically stable and inhalational agents with least side effects continued even after Isoflurane as a result of which, DESFLURANE, a fluorinated methyl ethyl ether was introduced in 1992, which was followed by SEVOFLURANE, a fluorinated methyl isopropyl ether in 1994. The least blood gas solubility of Desflurane and Sevoflurane facilitates rapid induction of anaesthesia, precise maintenance of end tidal concentrations of inhalational agents helps in maintaining depth of anaesthesia and fast recovery depending on duration of administration of these agents. ${ }^{1}$

In this study, we are comparing the efficacy of Desflurane and Sevoflurane, with regards to faster emergence, recovery, intraoperative haemodynamic profile and postoperative adverse effects if any in surgical procedures lasting less than 120 minutes. 


\section{MATERIALS AND METHODS}

A randomised, single-blinded, prospective study done in King George Hospital, Visakhapatnam by Department of Anaesthesia after approval from institutional ethics committee between October 2014 to April 2016 to compare intraoperative haemodynamics and postoperative recovery profile between Desflurane and Sevoflurane used for maintenance of anaesthesia in 60 adult patients planned for surgical procedures lasting less than 120 minutes under general anaesthesia.

The actual calculated sample size was 27 in each group, by taking time to achieve Modified Aldrete Score of 9 from other published clinical trials (Jindal etal), ${ }^{2}$ was taken with effect size 0.7, Mean difference of 5.4 and SD of 7.6 with $70 \%$ power, $95 \%$ confidence interval and 0.05 level of significance. Considering Dropouts, Unavoidable circumstances in prolongation of duration of surgical procedure and to improve the power of the study we took the sample size as sixty (60).

Patients with age group 18 to 60 years planned for surgical procedure under general anaesthesia with ASA I and ASA II were included in study.

Patients with any drug abuse, Renal, Hepatic, Cardiopulmonary diseases, morbidly obese patients, Pregnant women were excluded from study.

Study protocol: The study is a Randomised interventional model. A trained researcher allocated the patients into two groups by using computer generated tables. Computer selects a random number from 1 to 60 and assigned participants to the trial groups, i.e., odd numbers to Group A (30) patients receiving Sevoflurane and even numbers to Group B (30) patients receiving Desflurane for maintenance of anaesthesia. Although the anaesthesiologist assigned to intervention, data analyst and outcome assessors were aware of group allocation, patients were blinded to allocation. A thorough Pre-anaesthetic Assessment was done in all the patients and were informed about the procedure and written consent was taken. All the patients were kept NBM for 6 hours prior to surgery, Premedicated with Inj. Ranitidine $150 \mathrm{mg}$ and Inj. Metoclopramide $10 \mathrm{mg}$ one hour before shifting to operation theatre. Intraoperative monitoring like ECG, Pulse Oximetry Non-invasive blood pressure monitoring were recorded. A large bore intravenous access was obtained. All patients were preoxygenated with $100 \%$ Oxygen for three minutes, Inj. glycopyrrolate $0.01 \mathrm{mg} / \mathrm{kg}$, Fentanyl $1-2 \mathrm{mcg} / \mathrm{kg}$ were given to the patients. Anaesthesia was induced with propofol 2 $\mathrm{mg} / \mathrm{kg} / \mathrm{IV}$, once loss of reflex of eyelashes is observed, inhalational agent either Sevoflurane or Desflurane was switched on. Inj. Vecuronium bromide $0.1 \mathrm{mg} / \mathrm{kg} / \mathrm{IV}$ was administered to facilitate endotracheal intubation. Patients subsequently received Sevoflurane $2 \%$ or Desflurane $6 \%$ along with $50 \%$ Nitrous oxide in Oxygen to attain Minimum alveolar concentrations of 1 MAC. Once 1 MAC was achieved, the gas flow was decreased to 1 litre each of Oxygen and Nitrous oxide, concentration of inhalational agent was reduced to lowest concentrations possible to maintain 1 MAC throughout the procedure from the time of induction till the end of the procedure. Heart rate, NIBP, $\mathrm{SpO}_{2}$, End tidal $\mathrm{CO}_{2}$ were measured intraoperatively. All patients received Inj. Ondansetron $1 \mathrm{mg} / \mathrm{kg} / \mathrm{IV}$, Inj. Paracetamol at the end of the procedure as standard protocol when skin suturing was started. Once the last suture was applied inhalational agent and Nitrous oxide was switched off and once the patient started spontaneous breathing, neuromuscular blockade was reversed with Inj. Neostigmine $60 \mathrm{mcg} / \mathrm{kg}$ and Inj. Glycopyrrolate $10 \mathrm{mcg} / \mathrm{kg}$. Time taken for spontaneous eye opening and response to verbal commands were noted and once Awake, Active, Haemodynamically stable and adequate tidal volume breaths were achieved, then the patient was extubated and shifted to PACU.

In the PACU, all the subjects were monitored and were observed for side effects like nausea, vomiting, drowsiness, delirium, pain postoperatively. Modified Aldrete score was recorded from the time of arrival to PACU at interval of 1 minute for first five minutes and every 5 minutes until a score of 10 is achieved. Once the score is 10 , then the patient is considered fit to shift to their respective wards. All the data were analysed using SPSS version 20, the parameters were expressed in mean \pm SD and Median wherever applicable. Statistical analysis of quantitative data among groups was done by student t-test, and for categorical values Chi-Square test is applied. P values no greater than 0.05 were considered as statistically significant.

\section{RESULTS}

\begin{tabular}{|c|c|c|c|c|}
\hline Group & $\mathbf{N}$ & Mean & S.D. & P value \\
\hline Age & & & & \multirow{3}{*}{0.110} \\
\hline Sevoflurane & 30 & 30.07 & 8.886 & \\
\hline Desflurane & 30 & 34.40 & 11.581 & \\
\hline
\end{tabular}

The study group were comparable and there is no statistically significant difference between sevoflurane and desflurane according to age.

\begin{tabular}{|c|c|c|c|c|c|}
\hline & Group & N & Mean & S.D. & P value \\
\hline $\begin{array}{c}\text { Duration } \\
\text { of surgery } \\
\text { (min.) }\end{array}$ & Sevoflurane & 30 & 92.67 & 28.062 & \\
\cline { 2 - 5 } & Desflurane & 30 & 92.83 & 25.820 & 0.981 \\
\hline
\end{tabular}

Table 2. Distribution of Study Groups According to Duration of Surgery

There is no statistically significant difference between the study groups according to Duration of Surgery. The Mean duration of surgery was $92.67 \pm 28.06 \mathrm{~min}$. in Sevoflurane group whereas it was $92.83 \pm 25.82 \mathrm{~min}$. in Desflurane group with a $P$ value of 0.981 and they were comparable.

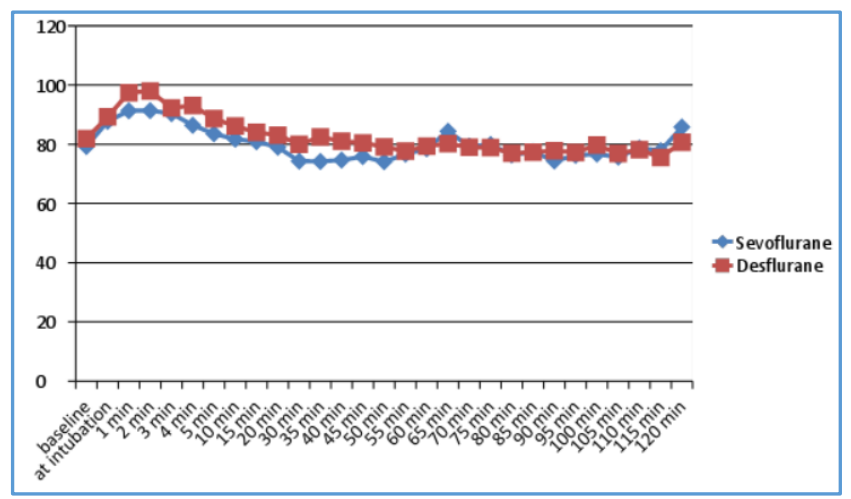

Graph 1. Distribution of Mean Heart Rate in between Study Groups for Duration of 120 minutes 
There was no statistical significant difference in the mean heart rates between sevoflurane and desflurane groups.

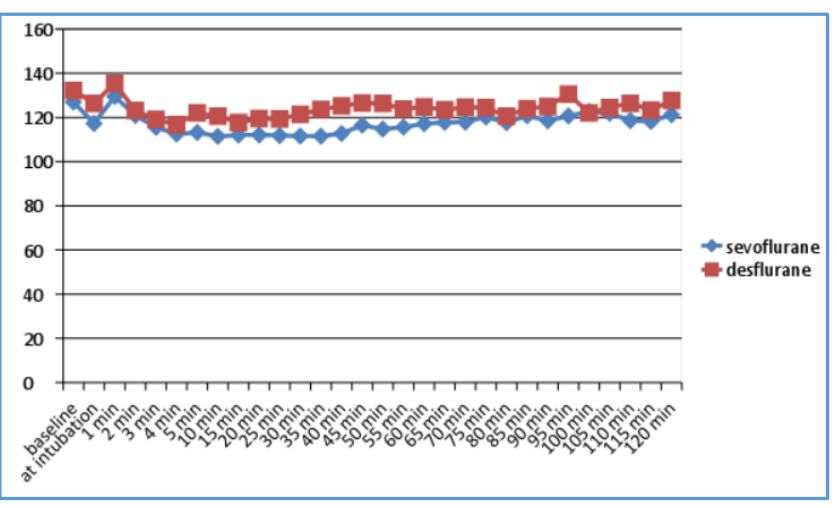

\section{Graph 2. Distribution of Mean Systolic Blood Pressure among Study Groups for Duration of 120 minutes}

There was no statistical significant difference in the mean systolic blood pressure between sevoflurane and desflurane groups.

\begin{tabular}{|c|c|c|c|c|c|}
\hline & Group & N & Mean & S.D. & P value \\
\hline Eye & Sevoflurane & 30 & 6.9667 & 1.58622 & \\
opening & Desflurane & 30 & 5.1767 & 1.48750 & $<0.001$ \\
\hline
\end{tabular}

Table 3. Distribution of Study Groups According to Duration Taken for Spontaneous Eye Opening

There is a statistical significant difference between study groups Sevoflurane and Desflurane with regards to spontaneous eye opening. In sevoflurane group, the time taken for spontaneous eye opening was $6.96 \pm 1.58 \mathrm{~min}$. whereas it was $5.17 \pm 1.48 \mathrm{~min}$. in desflurane group with a mean difference of $1.79 \mathrm{~min}$. which was clinically significant.

\begin{tabular}{|c|c|c|c|c|c|c|c|c|c|}
\hline Time & \multicolumn{7}{|c|}{ Modified Aldrete Score } \\
\hline & \multicolumn{6}{|c|}{ Sevoflurane } & \multicolumn{5}{c|}{ Desflurane } \\
\hline $\begin{array}{c}1 \\
\text { min }\end{array}$ & 30 & 5.43 & 0.898 & 5.00 & 30 & 5.30 & 8.37 & 5.0 & 6.0 \\
\hline $\begin{array}{c}2 \\
\text { min }\end{array}$ & 30 & 5.73 & 1.015 & 5.50 & 30 & 6.10 & 1.213 & 6.0 & 0.205 \\
\hline $\begin{array}{c}3 \\
\text { min }\end{array}$ & 30 & 6.60 & 1.037 & 6.00 & 30 & 7.87 & 1.196 & 8.0 & 0.000 \\
\hline $\begin{array}{c}4 \\
\text { min }\end{array}$ & 30 & 7.30 & 0.915 & 7.50 & 30 & 8.87 & 0.973 & 9.0 & 0.000 \\
\hline $\begin{array}{c}5 \\
\text { min }\end{array}$ & 30 & 8.30 & 0.794 & 8.00 & 30 & 9.70 & 0.702 & 10.0 & 0.000 \\
\hline $\begin{array}{c}10 \\
\text { min }\end{array}$ & 30 & 9.07 & 0.828 & 9.00 & 30 & 10.0 & 0.0 & 10.0 & 0.000 \\
\hline $\begin{array}{c}15 \\
\text { min }\end{array}$ & 30 & 9.77 & 0.430 & 10.00 & 30 & 10.0 & 0.0 & 10.0 & 0.005 \\
\hline $\begin{array}{c}20 \\
\text { min }\end{array}$ & 30 & 10.00 & 0.000 & 10.00 & 30 & 10.0 & 0.0 & 10.0 & 1.000 \\
\hline $\begin{array}{c}25 \\
\text { min }\end{array}$ & 30 & 10.00 & 0.000 & 10.00 & 30 & 10.0 & 0.0 & 10.0 & 1.000 \\
\hline $\begin{array}{c}30 \\
\text { min }\end{array}$ & 30 & 10.00 & 0.000 & 10.00 & 30 & 10.0 & 0.0 & 10.0 & 1.000 \\
\hline & Table 4. Mean and Median Modified Aldrete \\
\hline & Score between the Two Groups \\
\hline
\end{tabular}

Time taken to achieve a median modified Aldrete score 10 in PACU was 5 min. in Desflurane whereas it took $15 \mathrm{~min}$. in patients who received Sevoflurane as primary anaesthetic agent for maintenance of anaesthesia.

This was both clinically and statistically significant.

\section{DISCUSSION}

The complete return of complex physiological functions after general anaesthesia with a short duration and reliable recovery has become more important for the conduct of anaesthesia. Due to the low solubility of Desflurane and Sevoflurane, they have the advantage of easier control of anaesthetic depth and more rapid recovery from anaesthesia. In our study, in patients belonging to ASA I and ASA II who underwent surgical procedures under general anaesthesia, we compared the postoperative recovery time for Desflurane and Sevoflurane and also the effects on the haemodynamics of the patient. Patient's eye-opening time, Modified Aldrete score of the patient was used as a unit for evaluation which comprises of activity, respiration, circulation, consciousness, and oxygen saturation of the patients which were recorded in the recovery room at $1 \mathrm{~min}$. interval for first five minutes followed by 10, 15 20, 25, 30 minutes respectively in PACU. MAS value of 10 was considered to indicate consciousness with clear headedness in our study and time required to reach an MAS of 10 was recorded.

In a study done by Jindal et $\mathrm{al}^{2}$ where they compared maintenance and emergence characteristics of Sevoflurane and Desflurane in day care gynaecological surgeries in outpatient anaesthesia, Intraoperative MAP and HR did not differ between the two groups $(p>0.05)$. In their study, haemodynamic stability was compared within patient groups where mean arterial blood pressure and heart rates were maintained within $20 \%$ of the baseline values during the course of anaesthesia. Similarly, in our study, there was no change in the heart rate and systolic blood pressure and it was maintained within $20 \%$ of baseline.

S Gergin, B Cervik, G B Yildrium et $\mathrm{al}^{3}$ concluded that intraoperative cardiovascular stability was easily achieved with both Sevoflurane and Desflurane, with MAP and HR maintained at $\pm 20 \%$ baseline values during the maintenance period. Although HR reduced below baseline value, reduction was less in Desflurane group. In conclusion, Desflurane like Sevoflurane maintains haemodynamic stability during intraoperative period. Although duration of anaesthesia was longer, early recovery profile was rapid in Desflurane group.

In our study when comparing groups of Sevoflurane and Desflurane, mean heart rate was higher in Desflurane group than Sevoflurane but maintained within $20 \%$ of baseline. This could probably be because of beta adrenergic activation induced by Desflurane which was mediated by release of plasma adrenaline and noradrenaline as in a study conducted by Weiskopf RB et al. $(4,5,6)$

In a study by Dexter et al, 7 patients receiving Desflurane exhibited more rapid emergence and followed commands, were extubated earlier and were oriented with clear headedness 1.0-1.2 min. earlier than those receiving Sevoflurane.

Xiaoguang Chen, Manxu Zhao, Paul F. 8 White et al evaluated the cognitive recovery profiles in elderly patients after general anaesthesia with Desflurane and Sevoflurane. 70 ASA I and II elderly patients (65 yrs.) undergoing total 
knee or hip replacement were randomly assigned into two groups, following induction of anaesthesia, either Desflurane $2 \%-4 \%$ or Sevoflurane $1 \%-1.5 \%$ with nitrous oxide $65 \%$ in oxygen.

The use of Desflurane was associated with more rapid emergence from anaesthesia $(6.3 \pm 2.4 \mathrm{~min}$. versus $8.0 \pm 2.8$ min.) and a shorter length of stay in the post anaesthesia care unit (213 $\pm 66 \mathrm{~min}$. versus $241 \pm 87 \mathrm{~min}$.).

Pensado Castineiras A, Rama maceiras P, Molins Gauna N et $\mathrm{al}^{9,10}$ conducted a study to compare the anaesthetic maintenance and early postoperative recovery and psychomotor function in patients who have been anesthetised with Desflurane, Sevoflurane or Isoflurane during prolonged open urological surgeries. Patients randomly assigned to receive Desflurane, Sevoflurane, Isoflurane with $\mathrm{N}_{2} \mathrm{O} 60 \%$ for anaesthetic maintenance. After the surgery, the anaesthetics were discontinued and time until eye opening, spontaneous breathing, extubation and orientation were recorded. Recovery time in the operating room was significantly shorter $(\mathrm{P}<0.05)$ after anaesthesia with Desflurane and Sevoflurane than compared to Isoflurane, with no significant differences between the Desflurane and Sevoflurane groups (duration of anaesthesia in min. $198 \pm 90,171 \pm 67$ and $191 \pm 79$; eye opening $7.6 \pm$ $3.7,7.8 \pm 3.0$ and $11.9 \pm 4.5$; time until extubation $7.8 \pm 3.0$ $8.3 \pm 3.0$ and $11.0 \pm 3.5$ for Desflurane, Sevoflurane and Isoflurane respectively).

In our study for anaesthesia time of 120 minutes observed in 60 patients, the mean eye-opening time was 5.17 $\min \pm 1.48 \mathrm{~min}$. in Desflurane group and in Sevoflurane group the duration was $6.96 \pm 1.58 \mathrm{~min}$. This could probably be due to faster washout of Desflurane because it has lower tissue solubility, which reduces anaesthetic accumulation in fat compartment with only minimal residual effects after cessation of administration of Desflurane and this could probably be the reason in rapid recovery even though used as a primary anaesthetic agent when compared to Sevoflurane. The current findings are consistent with previously published comparative studies demonstrating that the faster emergence from Desflurane when compared to Sevoflurane anaesthesia.

Emergence agitation although well documented in the clinical literature, still has uncertainties and confusion abound on this subject because of the absence of a clear definition and lack of reliable and valid assessment tools. Jindal et al compared Sevoflurane and Desflurane in 100 females undergoing day care laparoscopic gynaecological surgeries. Since the time of administration of reversal agent, patients in Desflurane group had significantly faster emergence and obeying commands than those in Sevoflurane group, however, this faster wakeup failed to translate into early readiness for discharge from the hospital.

In our study, we found that patients receiving Desflurane had faster emergence during recovery. This could probably be due to lesser quantity of drug absorbed and metabolised in the body, low blood/gas solubility of Desflurane, shorter duration of surgery, low flow anaesthesia technique used while administering, leading to rapid recovery from anaesthesia. A rapid recovery decreased the time needed to move the patient from the operating room to PACU.

Jalan Ergonenec, Tolga Ergonenec and Gulsen Bican et al11 compared in their study on recovery time of Sevoflurane and Desflurane and the effects of anaesthesia on mental and psychomotor and pain, mean time to reach modified Aldrete score 8 in their study. Emergence recovery, MAS initially and at 5 and 10 min. were higher in groups receiving Desflurane compared to Sevoflurane.

Jindal et $\mathrm{al}^{2}$ compared Sevoflurane and Desflurane in 100 females undergoing day care laparoscopic gynaecological surgeries. From the time of administration of reversal agent, patients in Desflurane group achieved Modified Aldrete score of $>9$ faster than Sevoflurane; however, this faster wakeup failed to translate into early readiness for home discharge.

Similarly, in our study, the median Modified Aldrete score 10, was achieved in 5 minutes time in Desflurane group, while it was 15 minutes in Sevoflurane group; this could probably be because of low blood/gas partition coefficient of Desflurane than Sevoflurane which helps in early clearheaded recovery of patients in PACU. The current findings are consistent with previously published comparative studies demonstrating the faster recovery from Desflurane versus Sevoflurane anaesthesia.

\section{CONCLUSION}

Patients receiving Desflurane had significant faster emergence and early recovery when compared to Sevoflurane, in short duration surgeries lasting less than 120 minutes. Both Desflurane and Sevoflurane had similar kind of haemodynamic profile, without any adverse effects during perioperative period while using these volatile agents as primary anaesthetics for maintenance of anaesthesia.

\section{REFERENCES}

[1] Whalen FX, Bacon DR, Smith HM. Inhaled anesthetics: a historical overview. Best Practice \& Research Clinical Anaesthesiology 2005;19(3):323-30.

[2] Jindal R, Kumra VP, Narani KK, et al. Comparison of maintenance and emergence characteristics after Desflurane or Sevoflurane in outpatient anaesthesia. Indian J Anaesth 2011;55(1):36-42.

[3] Gergin S, Cevik B, Yildirim GB, et al. Sevoflurane Vs Desflurane: haemodynamic parameters and recovery characteristics. Internet J Anaesthesiol 2005;9:1.

[4] Weiskopf RB, Eger EI, Daniel M, et al. Cardiovascular stimulation induced by rapid increases in Desflurane concentration in humans results from activation of tracheopulmonary and systemic receptors. Anesthesiology 1995;83(6):1173-8.

[5] Yonker-Sell AE, Muzi M, Hope WG, et al. Alfentanil modifies the neurocirculatory responses to Desflurane. Anesth Analg 1996;82(1):162-6.

[6] Weiskopf RB, Eger EI 2nd, Noorani M, et al. Fentanyl, esmolol and clonidine blunt the transient cardiovascular stimulation induced by Desflurane in humans. Anesthesiology 1994;81(6):1350-5.

[7] Dexter F, Tinker JH. Comparison between Desflurane and isoflurane or propofol on time to following commands and time to discharge. A meta-analysis. Anesthesiology 1995;83(1):77-82.

[8] Chen $\mathrm{X}$, Zhao M, White PF, et al. Cognitive function after general anesthesia in elderly patients: a comparison of Desflurane and Sevoflurane. Anesth Analg 2001;93(6):1489-94. 
[9] Castineiras PA, Maceiras RP, Gauna MN, et al. Immediate anesthesia recovery and psychomotor function of patient after prolonged anesthesia with Desflurane, sevoflurane or isoflurane. Rev Esp Anesthesiol Reanim 2000;47(9):386-92.

[10] Tarazi, Philip J. Recovery after Desflurane and Sevoflurane. Clin Anaesth 2009;109:387-93.
[11] Ergonenc J, Ergonenc T, Ldin K, et al. The recovery time of sevoflurane and Desflurane and the effects of anesthesia on mental and psychomotor function and pain. Anesth Essays Res 2014;8(3):367-71. 